Please send trade news information and illustrations to Arveen Bajaj at the BDJ, 64 Wimpole Street, London W1G 8YS. Trade news is supplied as a service to the reader and does not imply endorsement by the BDJ. Normal and prudent research should be exercised before purchase of use of any product mentioned.

\section{TRADE NEWS \\ WHAT'S NEW}

\section{High polish}

New to the KerrHawe range is the HiLuster Plus Polishing System. The aluminium oxide incorporated Gloss Plus Polisher allows for pre and gloss polishing in one step. The optimum flexibility of the silicone matrix allows adaptation to the restoration allowing polishing of all the varying angles.

The system has a combination of shapes, such as flame, minipoint, cup and disc.

Reader response number 50

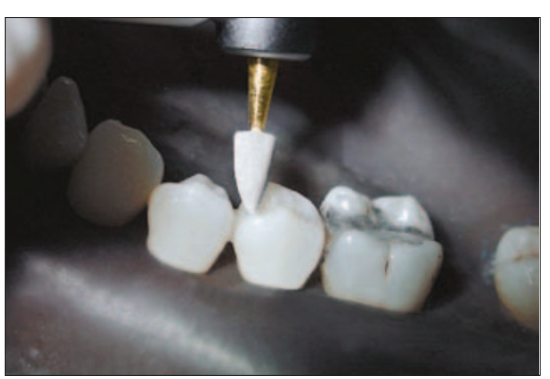

\section{Toy offer}

Alkapharm is offering free Fisher-Price toys with purchases this Christmas, which practices can receive by placing orders for any combination of two or more of the products from the range. The products included are Alkaspray-plus 5 litre economy refill, Alkazyme 750gm, powder concentrate, Alkazyme 100 water soluble sachets, Alkacide 1 litre concentrate, System-2, 5 litre concentrate and Alkapharm Wipes 250 wipe tub (case of 12 tubs).

Every qualifying purchase made during November and December is rewarded with a choice from a selection of Fisher-Price toys each worth up to $£ 19.99$.

Reader response number 51

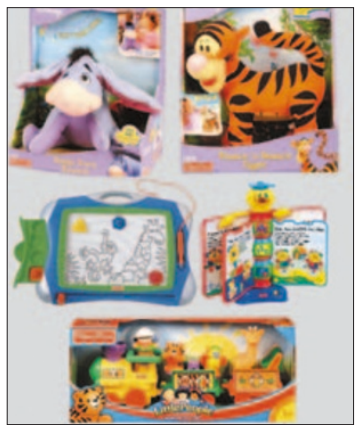

Brush pressure

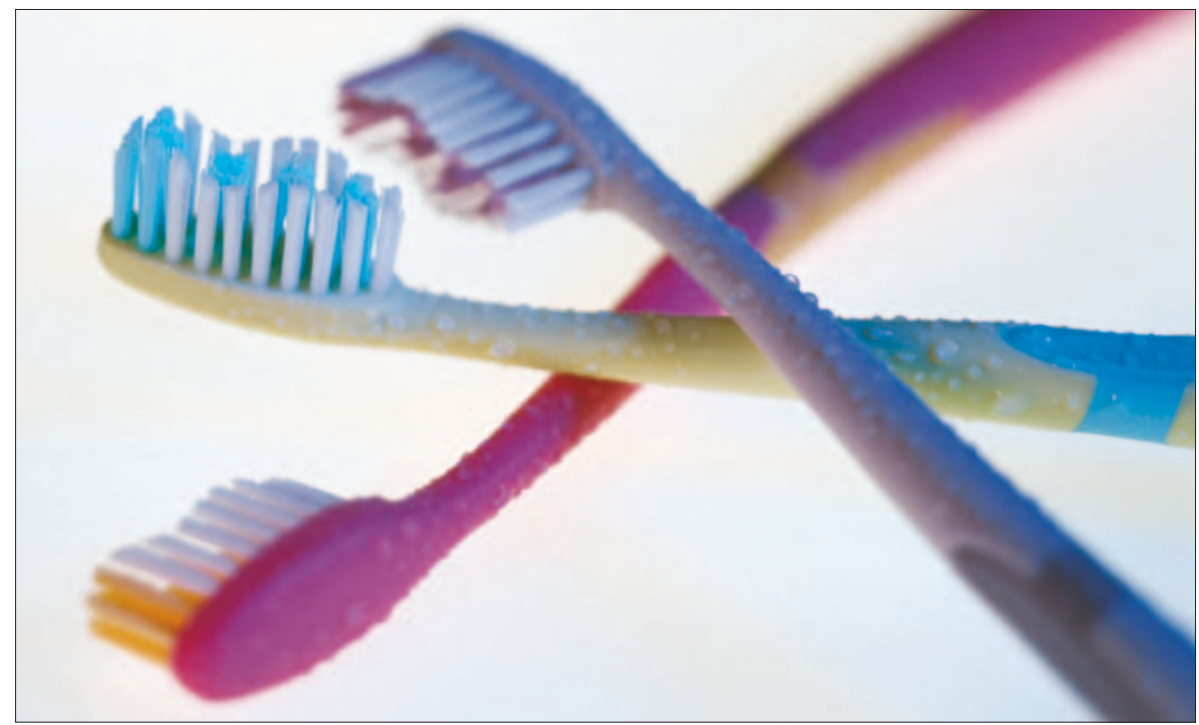

Wisdom have launched a new product that claims to help stop heavy handed tooth brushing.

The handle of the Wisdom Click toothbrush will bend backwards with a noticeable 'click', reminding the individual to adjust their brushing pressure.

The pressure control system uses patented technology that alerts the user when the pressure against the teeth and gums becomes too hard.

To continue brushing normally after it has clicked, the user must reduce their brushing pressure and allow the brush head to return to its original position.

Wisdom Click is available in two textures: medium and soft both with a combination of V-shaped bristles and active tip.

Wisdom claim that the simple, slender handle design makes it comfortable to use and hygienic with no toothpaste traps. Reader response number 52

\title{
Oral preparation launched
}

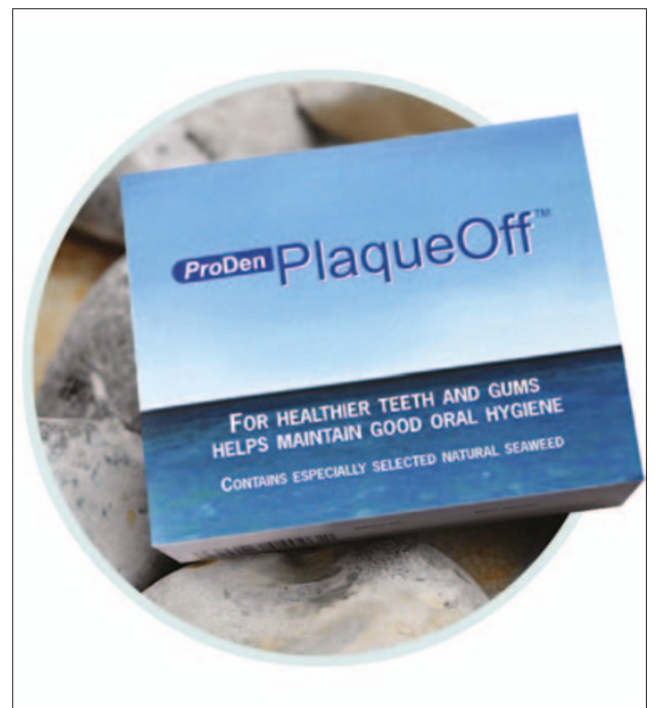

Molar Ltd has recently launched a new product that it claims may act as an adjunct to the routine oral hygiene of patients.

ProDen PlaqueOff is an oral preparation which contains especially selected seaweed from the ascophyllum nodosum family (SW1313).

It is rich in iodine, minerals, trace elements and free from artificial colours, preservatives, gluten and sugar.

Patients ingest 1-2 tablets daily with food and it is thought to disrupt plaque biofilm, reducing adherence of plaque and softening existing calculus, according to Molar.

Reader response number 53 


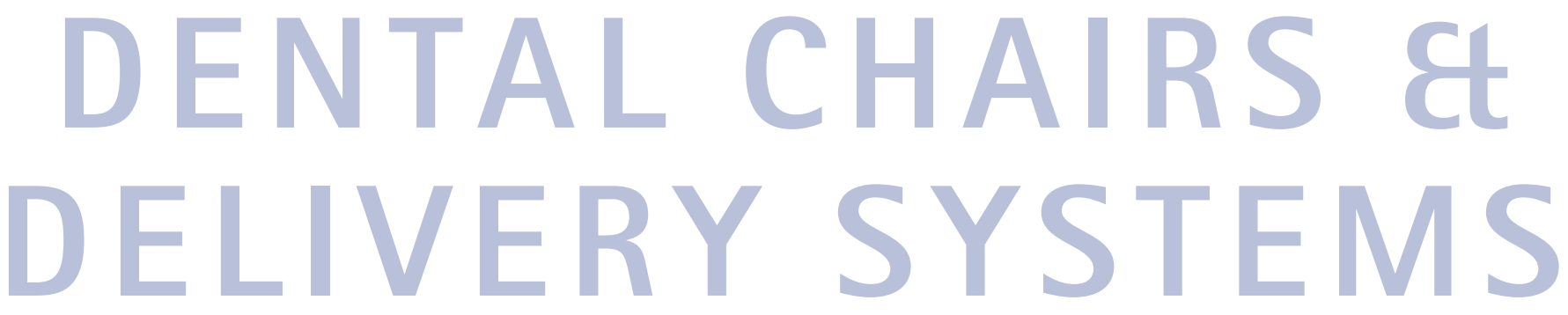

\section{Streamlined chair}

The A-dec 500's slim-profile headrest and ultra-thin backrest provides more legroom, so operators can work in a more comfortable position. The anatomically formed backrest and seat cushion cradle patients by reducing pressure points and provides support. The result is a chair that offers streamlined access for the dental team and, at the same time, comfortable seating for patients.

Each A-dec 500 module is designed to create 'synergy' between elements, people, and procedures in the treatment room and is offered in a choice of seamless or sewn upholstery styles with a total of 24 colour options.

Reader response number 54

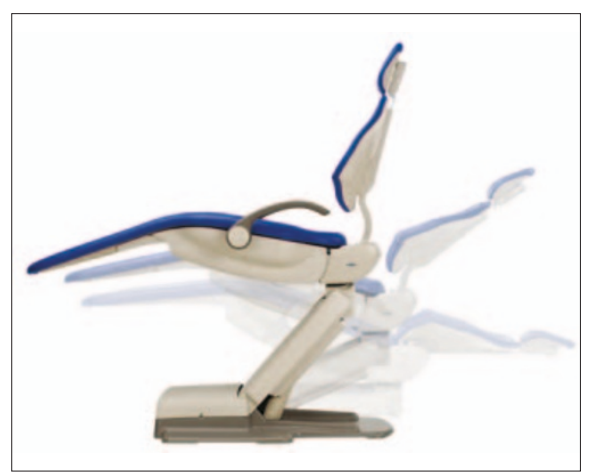

\section{Revolving seat}

Tridac's range of anatomical stools have been developed to give optimum support and a high degree of comfort when performing most dental procedures.

The stools have a revolving seat with an adjustable backrest tilt and seat height. Height adjustment is by gas lift and a footrest ring can be provided to give addi-

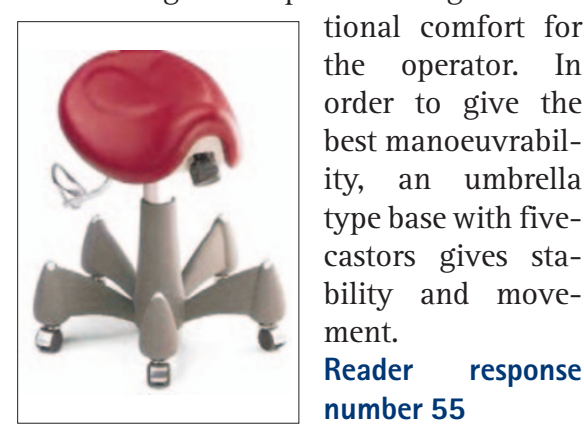

Unique turn option

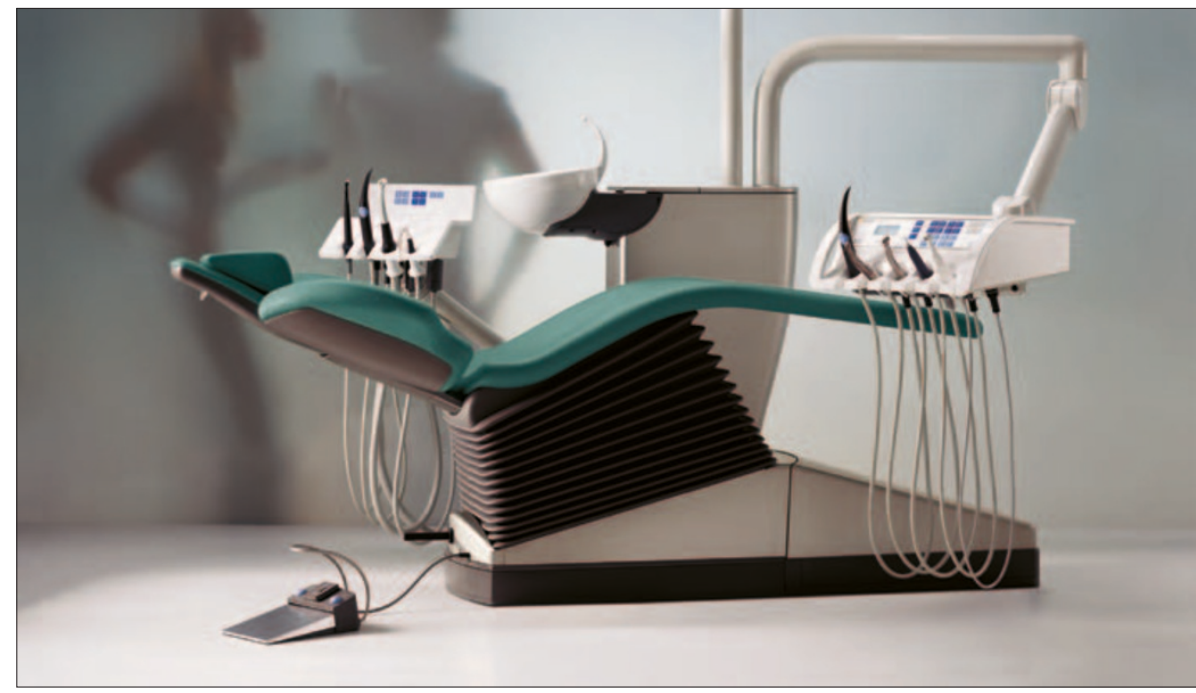

The $\mathrm{C}^{+}$Turn from Sirona Dental Systems has a unique turn option which makes it easy to convert it for right-handed or lefthanded operation.

It requires an area of $265 \times 270 \mathrm{~cm}$ to convert, and the tray is not attached to the dentist's element so it can be freely manoeuvred, is height-adjustable and can be positioned at different angles along the longitudinal axis of the chair.

The dental chair is fitted with a special support arm that permits the individual positioning of the dentist's element to be moved to most treatment positions. The support features a pneumatic brake mechanism and a weight compensation system that can be adjusted to cope with different loads when lowering or raising the operative elements or the tray.

Reader response number 56

\section{Ergonomical design}

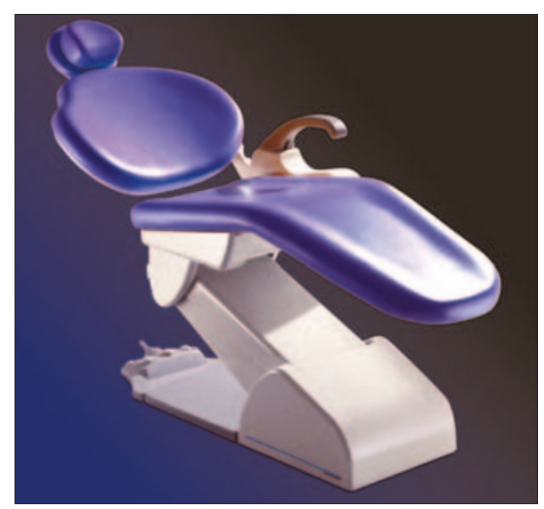

The Galla chair from Dabi Atlante is ergonomically designed to give maximum comfort to both the patient and the dental professional, its makers claim.

Its minimum height in relation to floor level gives dentists of any stature comfort during clinical procedures and allows easy patient access and exit. It features a large backrest with a sculptured anatomical curvature to ensure the patient is supported and relaxed, even during long dental procedures. It also allows the dentist unconstrained access to the patient, as does the small-sized base. A magnetic headrest pad means the patients' head can be positioned anywhere on the headrest or backrest. Three work positions can be chosen and pre-programmed by the dentist for ease of use and zeroposition return, reflector, backrest and seat movements are controlled via an easy-to-clean footswitch. A package consisting of a Galla chair, cuspidor, light and Flex Cart which includes professional fitting and installation is available from Red Apple.

Reader response number 57 


\section{Easy clean surfaces}

The Kavo Estetica Sensus 1066 dental unit has a choice of either an 'articulated' or 'bracket table' delivery system.

Other features included in the packages are removable, disinfectable positioning handles, sensor controls, priority instrument switching, instrument tray, autoclavable three function syringe, height adjustable arm, easy clean surfaces, air/water filters and built in pressurised auto-fill water system and motorised automatic spittoon.

The unit incorporates instrument outlets with a fibre optic light facility, and the options of innovative air or electric brushless induction motors with fibre optics. Clinicians' upgrading options with the

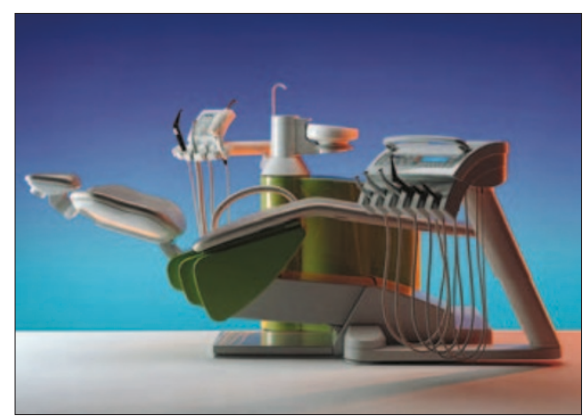

Sensus 1066 dental unit include specialist tools such as a camera, ultra sonic scaler, air polishing units, an electrosurgery unit and saline solution pump. It is available form Henry Schein.

Reader response number 58

\section{Left or right-handed use}

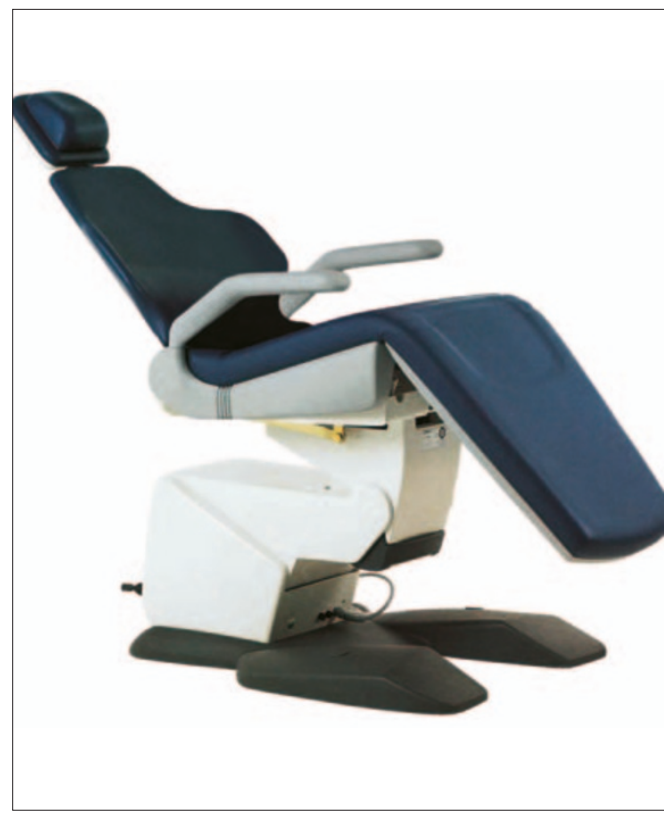

The Tridac Contour unit offers a clean, straightforward and neat appearance, its makers claim.

Internal umbilicals and service connections to the chair ensure no untidiness in the surgery and the Contour unit is available with a variety of instrumentation depending on the practice budget and application. This ranges from a simple selection of air tools through to sophisticated electronic devices.

Adaptable for left or right-hand use without any tools, the unit is flexible for use by all clinicians.

Systems can be purchased in either a cabinet, cart or chair mounted configuration and are available with a wide selection of colour combinations.

Reader response number 59

\section{Auto control delivery system}

The Fedesa Supra from Henry Schein is an electro-hydraulic chair which features a double articulating headrest and drop armrest to enhance patient comfort and ease of entry, as well as incorporating three programmes. These are easy programme positioning, rinse position and return to zero.

The auto shut-off operating light with adjustable intensity and excellent colour matching properties delivers 5000K white light or daylight at 2500 lux.

The Fedesa Supra's assistant's console is situated on the articulating arm for easy access, and includes a tray and high velocity evacuation (HVE) suction systems.

The unit incorporates three handpieces, including two fibre optic outlets, and an auto control delivery system.

The chair is available in eleven colours to complement any surgery décor and comes with a two year parts guarantee as standard.

Reader response number 60

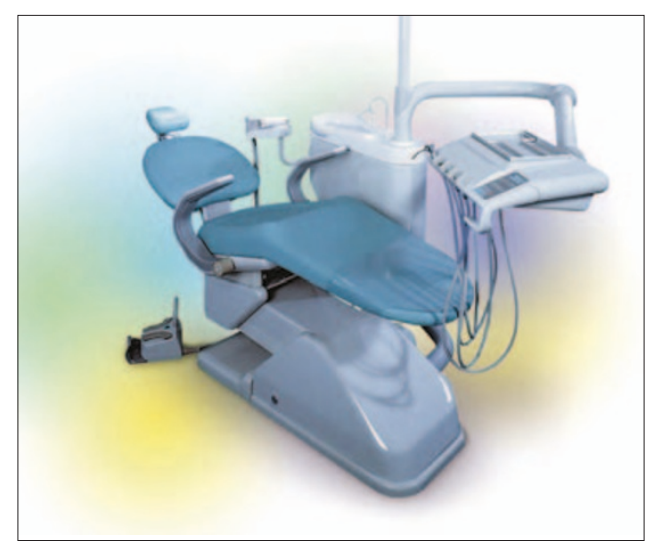

